\title{
Relationship of motor symptoms, intellectual impairment, and depression in Parkinson's disease
}

\author{
STEVEN J HUBER, GEORGE W PAULSON, EDWIN C SHUTTLEWORTH \\ From the Ohio State University College of Medicine, Department of Neurology, Columbus, Ohio, USA
}

SUMMARY The relationship between severity of disease, intellectual impairment, and depression was examined in 50 patients with Parkinson's disease. A significant correlation between severity of disease and intellectual impairment suggests that both may result from the same subcortical lesions. Depression was not significantly related either to severity of disease or to intellectual impairment. This suggests that the relationship between severity of disease and intellectual impairment was not an artifact of increasing depression. Severity of rigidity and of bradykinesia did predict severity of intellectual decline, but severity of tremor predicted better intellectual status. Patients with a predominance of tremor may have a more benign clinical course as well as better intellectual function than patients with a predominance of rigidity and bradykinesia.

Aside from the inevitable movement disorder, depression and intellectual impairment are common in patients with Parkinson's disease. The relationship between these symptoms, however, is uncertain. Specific intellectual impairments involving memory, visuospatial skills, and cognition have been identified in patients with Parkinson's disease, ${ }^{1-7}$ and one study estimates that over $90 \%$ of patients have at least one significant impairment. ${ }^{8}$ The pathophysiology of the intellectual impairment in Parkinson's disease is unclear. Several authors ${ }^{36910}$ have suggested that lesions within the brainstem and basal ganglia, responsible for motor symptoms, may in addition produce intellectual deficits in Parkinson's disease. A significant relationship between severity of motor symptoms and intellectual impairment ${ }^{11-15}$ suggests that nigral and striatal structures may be related to the pathophysiology of intellectual dysfunction in Parkinson's disease.

While depression is common in patients with Parkinson's disease, ${ }^{16-21}$ the relationship between

Address for reprint requests: Steven J Huber, PhD, Department of Neurology, 425 Means Hall, 1655 Upham Drive, Columbus, Ohio 43210, USA.

Received 14 August 1987 and in revised form 2 February 1988. Accepted 10 February 1988 depression and disease severity is unclear. One study found a significant association between severity of depression and motor symptoms, ${ }^{19}$ while others found no such relationship. ${ }^{132021}$ The lack of a positive relationship between severity of disease and depression is suggestive of endogenous rather than reactive depression. The relationship between depression and intellectual impairment is also unclear. One report demonstrated a positive correlation $^{13}$ although others have failed to confirm this relationship. ${ }^{1922}$

Disagreement among these reports is not surprising since Parkinson's disease is such a heterogeneous disorder and comparisons among different populations could be expected to vary. Only one previous study ${ }^{13}$ has examined the relationship between severity of motor, intellectual, and depressive symptoms in the same group of patients with Parkinson's disease, and this was the sole report of a significant relationship between severity of depression and intellectual impairment. Since depression can have a debilitating effect on intellectual performance, ${ }^{23-25}$ it is at present uncertain whether there is a unique relationship between severity of disease and intellectual impairment in Parkinson's disease. We examined the relationship between severity of the movement disorder, intellectual impairment, and depression in $\mathbf{5 0}$ patients with Parkinson's disease. 


\section{Methods}

Patients Fifty patients ( 32 males and 18 females) with idiopathic Parkinson's disease participated. None of the patients had undergone thalamotomy and none had a previous history of stroke. All patients were taking levodopa-carbidopa and the average dose was $470 \mathrm{mg}$ (range $=200 \mathrm{mg}$ to $1250 \mathrm{mg}$ ). None of the patients met DSM-III criteria for dementia. ${ }^{26}$ This patient group had a range in age from 37 to 77 years (mean $=64 \cdot 32)$; years of education ranged from 8 to 20 (mean $=14.5)$, and duration of disease varied from 1 to 15 years $($ mean $=4.98)$.

Procedures All evaluations were conducted in a single sesssion lasting approximately 1 hour. All subjects gave informed consent prior to participation.

Intellectual assessment Intellectual status in patients with Parkinson's disease was evaluated using the Mini--Mental State (MMS) examination. ${ }^{27}$ This is a brief evaluation of mental function that is well accepted and correlates with more extensive intellectual assessments such as the Wechsler Adult Intelligence Scale. ${ }^{2728}$ Subtests include orientation, registration, recall, calculation, and language. Maximum score is $\mathbf{3 0}$.

Clinical evaluation Each patient with Parkinson's disease was examined by the complete clinical condition scale (CCS) developed by Hoehn and Yahr. ${ }^{29}$ Twelve signs and symptoms were rated on a scale from 0 to 4 , with 0 indicating the absence of a symptom and 4 indicating extreme severity. Symptoms rated were: rigidity, resting tremor, action or postural tremor, bradykinesia, finger agility, foot agility, gait, posture, postural stability, facial expression, speech, and ability to arise from a chair. This scale has a range of $0-48$. Depression Depressive symptoms were measured using the Hamilton Depression Scale (HDS). ${ }^{30}$ Each of the 21 symptoms related to depression were rated by the investigator during an interview with the patient. Items were rated according to the scale specified for each symptom. This measure has a range of $0-65$.

\section{Results}

The mean Mini-Mental State Examination (MMS) score was $26 \cdot 66$ (range $=22-30$ ), the mean Hamilton depression score (HDS) was 12.24 (range $=3-30$ ), and the mean complete clinical score (CCS) was 14.5 (range $=3-34$ ). The relationship between these measures was analysed by the Pearson product-moment correlational procedure. Severity of tremor, bradykinesia, and rigidity were also analysed with respect to both MMS and HDS measures. Since the ratings for individual symptoms are non-parametric data, Spearman's rank-order correlation procedure (rho) was used.

There was a significant negative correlation between intellectual function (MMS) and the clinical evaluation measure (CCS) $(r=-0.77, p<0.0001)$. This finding suggests that as severity of motor symptoms increased, performance on the measure of intellectual function decreased (fig). In addition to severity of disease, age $(r=-0.31, p<0.05)$ had a significant influence on MMS performance. MMS performance was not significantly related to duration of disease or years of education. None of these factors was significantly related to disease evaluation. In order to determine whether age influenced the correlation between the MMS and CCS, a partial correlation was performed to control for age. Controlling for age had essentially no effect on the correlation coefficient $(r=-0 \cdot 76)$. This suggests that the relationship between severity of disease and intellectual impairment cannot be explained as an artifact of aging.

We also examined the relationship of the classic triad of symptoms in Parkinson's disease (rigidity, bradykinesia, and tremor) as a function of intellectual impairment. Results indicated a significant negative correlation between intellectual impairment and both rigidity (rho $=-0.79, \mathrm{p}<0.01$ ) and bradykinesia (rho $=-0.70 \mathrm{p}<0.01$ ). These findings suggest that severity of both rigidity and bradykinesia were associated with increased intellectual impairment in patients with Parkinson's disease. Just the opposite pattern was seen when tremor was compared to intellectual performance. There was a significant but positive correlation between tremor and MMS performance (rho $=0.38, \mathrm{p}<0.01$ ). This suggests that patients with relatively mild tremor had relatively more severe intellectual impairment.

We did not find a significant relationship between severity of disease (CCS) and depression (HDS) $(r=0 \cdot 14)$. Severity of intellectual impairment (MMS) and depression were also not significantly related $(r=-0 \cdot 11)$. That is, severity of depression in patients $\frac{0}{0}$. with Parkinson's disease would appear to be unrelated $\stackrel{\infty}{\ominus}$ either to clinical condition or intellectual function.

\section{Discussion}

We found a significant association between severity of

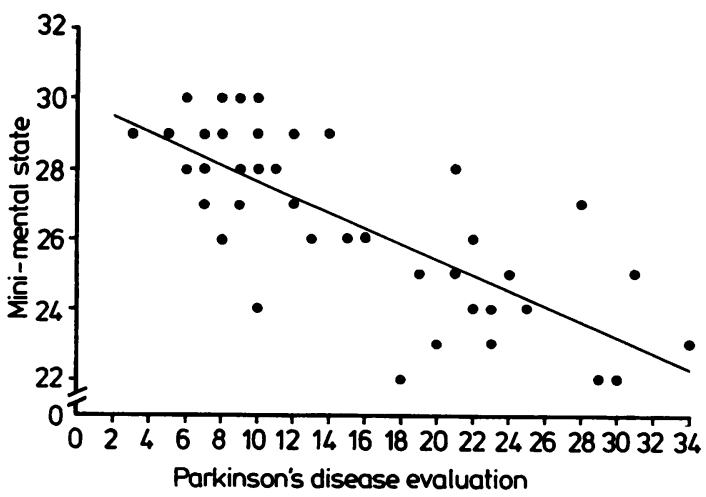

Fig Correlation between intellectual performance and severity of Parkinson's disease $(r=-0 \cdot 77)$. 
the movement disorder and intellectual impairment in patients with Parkinson's disease. This relationship has been a consistent finding in previous reports. ${ }^{11-15}$ The significance of this relationship is the suggestion that the subcortical lesions responsible for the movement disorder may also be implicated in the pathophysiology of the intellectual impairment in patients with Parkinson's disease. This is consistent with animal research which has demonstrated that lesions in the basal ganglia produce specific cognitive deficits. $^{31}$

One potentially confounding factor in the relationship between intellectual and motor function is that of depression. Depression is common in patients with Parkinson's disease, ${ }^{16-21}$ and depression can have a debilitating effect on intellectual function. ${ }^{23-25}$ Since depression is common and because of its potential influence on intellectual performance, this factor must be considered when examining the relationship between motor symptoms and intellectual function in patients with Parkinson's disease. In a previous study which also examined all three factors, Mayeux et $a l^{13}$ found a significant relationship between depression and intellectual impairment. However, previous research ${ }^{120-22}$ did not find a significant relationship when intellectual function was compared with depression. We found a significant relationship between severity of intellectual inpairment and motor dysfunction, but not depression, suggesting a unique relationship between cognitive and motor symptoms in patients with Parkinson's disease. The reliability of this finding awaits future research.

The lack of a relationship between severity of disease and depression in our study as well as in previous research ${ }^{132021}$ suggests that the depression may be an integral part of Parkinson's disease rather than a reaction to physical disability. Other findings are consistent with this hypothesis. Patients with Parkinson's disease are more likely to develop depressive symptoms compared to other patient groups with chronic neurologic disorders who were assumed to suffer comparable disability. ${ }^{172021}$ In some patients with Parkinson's disease depressive symptoms may antedate the onset of motor symptoms. ${ }^{131632}$ Finally, patients with Parkinsonism and depression may be biochemically distinct from patients with Parkinson's disease who are not depressed. In a recent study, Mauyeux et $a l^{33}$ found approximately $35 \%$ of the patients met DSM-III criteria for depression. Unlike patients without depression and normal controls, the patients who were depressed had decreased levels of serotonin, a finding similar to patients with primary depression. In summary, it would appear that depression in patients with Parkinson's disease is not related to severity of disease, and depressive symptoms may be biochemically distinct from the movement disorder.

There appears to be a distinct relationship between intellectual impairment in patients with Parkinson's disease and the classic triad of motor symptoms: bradykinesia, rigidity, and tremor. Our findings and previous research found a significant relationship between severity of bradykinesia and intellectual impairment. ${ }^{611-143536}$ All but one previous study ${ }^{11}$ also found a significant relationship between severity of rigidity and intellectual impairment. ${ }^{121335} \mathrm{We}$ also found that more severe rigidity is associated with increasing intellectual impairment. The relationship between tremor and intellectual impairment is clearly different. One report ${ }^{12}$ found that like rigidity and bradykinesia, severity of dementia in Parkinson's disease was also associated with more severe tremor. This is in contrast to Lieberman ${ }^{14}$ who had the clinical impression that demented patients with Parkinson's disease actually had less severe tremor compared to patients who were not demented. Another report ${ }^{11}$ found an inverse relationship between severity of tremor and spatial orientation memory performance. Consistent with these latter two reports, we found that patients with relatively more severe tremor tend to have less intellectual impairment.

There may be two distinct subtypes of Parkinson's disease. It has long been recognised that patients who have predominant tremor tend to have a more benign clinical course compared with patients with predominant bradykinesia and rigidity. ${ }^{29}{ }^{37}$ In addition to clinical differences, a cognitive distinction may also be present. Patients with predominant bradykinesia and rigidity may suffer more severe cognitive impairment compared to patients with predominant tremor. These two subtypes of Parkinson's disease may also be distinct in terms of the underlying pathophysiology. ${ }^{38}$ This hypothesis may best be examined by longitudinal studies of patients with predominant tremor or rigidity and bradykinesia at onset and followed for progression of disease and intellectual impairment.

This research was supported in part by a grant from the United Parkinson Foundation.

\section{References}

1 Celesia GG, Wanamaker WM. Psychiatric disturbances in Parkinson's disease. Dis Nerv Syst 1972;33:577-83.

2 Reitan RM, Boll TJ. Intellectual and cognitive functions in Parkinson's disease. $J$ Consult Clin Psychol 1971;37:364-69.

3 Loranger AW, Goodel $\mathrm{H}$, Lee JE, et al. Intellectual impairments in Parkinson's syndrome. Brain 1972;95:405-12.

4 Martin WE, Loewenson RB, Resch JA, et al. 
Parkinson's disease: Clinical analysis of 100 patients. Neurology 1973;23:783-90.

5 Boller F, Passatiume D, Keefe NC, et al. Visuospatial impairments in Parkinson's disease. Arch Neurol 1984;41:485-90.

6 Garron DC, Klawans HL, Narin F. Intellectual functioning of persons with idiopathic Parkinsonism. $J$ Nerv Ment Dis 1972;154:445-52.

7 Halgin R, Riklan M, Misiak H. Levodopa, parkinsonism, and recent memory. $J$ Nerv Ment Dis 1977;164:268-72.

8 Pirozzolo FJ, Hansch EC, Mortimer JA, et al. Dementia in Parkinson's disease: A neuropsychological analysis. Brain and Cogn 1982;1:71-83.

9 Albert M. Subcortical dementia, in Alzheimer's Disease. In: Katzman R, Terry RD, Bick KL, eds. Senile Dementia and Related Disorders. New York: Raven Press, 1978.

10 Joynt RF, Shoulson I. Dementia. In: Heilman KM, Velenstein E, eds. Clinical Neuropsychology. Oxford: Oxford University Press, 1975:475-502.

11 Mortimer JA, Pirozzolo FJ, Hansch EC, et al. Relationship of motor symptoms to intellectual deficits in Parkinson's disease. Neurology 1982;32:133-7.

12 Marttila RJ, Rinne UK. Dementia in Parkinson's disease. Acta Neurol Scand 1976;54:431-41.

13 Mayeux R, Stern Y, Rosen J, Leventhal J. Depression, intellectual impairment, and Parkinson's disease. Neurology 1981;31:645-50.

14 Lieberman AN. Parkinson's disease: a clinical review. Am J Med Sci 1974;267:66-80.

15 Growdon JH, Corkin S, Desclos G, Rosen TJ. Hoehn and Yahr stages predict the extent of cognitive deficit in Parkinson's disease. Neurology 1987;37:157.

16 Mindham RHS. Psychiatric symptoms in parkinsonism. J Neurol Neurosurg Psychiatry 1970;33:181-191.

17 Warburton JW. Depressive symptoms in Parkinson patients referred for thalamotomy. J Neurol Neurosurg Psychiatry 1967;30:368-370.

18 Brown GL, Wilson WP. Parkinsonism and depression. South Med J 1972;65:540-5.

19 Mindham RHS, Marsden CD, Parkes JD. Psychiatric symptoms during L-dopa therapy for Parkinson's disease and their relationship to physical disability. Psycholog Med 1976;6:23-33.

20 Horn S. Some psychological factors in parkinsonism. $J$ Neurol Neurosurg Psychiatry, 1960;23:56-61.

21 Robbins AH. Depression in patients with parkinsonism. Br J Psychiatry 1976;128:141-5.
22 Lieberman A, Dziatoloski M, Kupersmith M, et al. Dementia in Parkinson's disease. Ann Neurol 1979;6:355-9.

23 Folstein MF, McHugh PR. Dementia syndrome of depression. In: Katzman R, Terry RD, Bick KL, eds Alzheimer disease: Senile Dementia and Related Disorders (vol 7). New York: Raven Press, 1978:87-93.

24 Miller WR. Psychological deficit in depression. Psychol Bull 1975;82:238-60.

25 Miller E, Lewis P. Recognition memory in elderly patients with depression and dementia: a signal detection analysis. J Abnorm Psychol 1977;86:84-6.

26 Diagnostic and Statistical Manual of Mental Disorders 3rd ed., edited by $\mathrm{J}$ Williams. American Psychiatric Association, Washington D.C., 1980.

27 Folstein MF, Folstein SE, McHugh PR. "Mini-mental state": A practical guide for grading the mental state of patients for the clinician. $J$ Psychiatry Res 1975;12:189-98.

28 McHugh PR, Folstein MF. Psychopathology of dementia. Implications for neuropathology, In: Katzman $\mathrm{R}$, ed. Congenital and Acquired Cognitive Disorders, New York: Raven Press, 1979:17-30.

29 Hoehn MM, Yahr MD. Parkinsonism: Onset, progression and mortality. Neurology 1967;17:427-42.

30 Hamilton M. A rating scale for depression. J Neurol Neurosurg Psychiatry, 1960;23:56-61.

31 Teuber HL. Complex functions of the basal ganglia. In Yahr MD, ed. The Basal Ganglia. New York: Raven Press, 1976, 151-68

32 Patrick HT, Levy DM. Parkinson's disease: a clinicalo study of 146 cases. Arch Neurol Psychiatr, 1922;7:711-20.

33 Mayeux R, Stern Y, Cote L, et al. Altered serotonin metabolism in depressed patients with Parkinson's disease. Neurology, 1984;5:642-8.

34 Praag HM, van and Haan, S. Central serotonin metabote lism and frequency of depression. Psychiatry Res? 1979;1:219-24.

35 Levita E. Riklan M, Cooper IS. Cognitive and perceptual performance in Parkinsonism as a function of age and neurological impairment. $J$ Nerv Ment Dis 1964:139:516-20.

36 Schwab RS, England AC, Peterson E. Akinesia in Parkinson's disease. Neurology 1959;9:65-72.

37 Zetusky WJ, Jancovic J, Pirozzolo FJ. The heterogeneity of Parkinson's disease: Clinical and prognostic implications. Neurology 1985;35:522-6.

38 Barbeau A, Roy M. Familial subsets in idiopathic Parkinson's disease. Can J Neurol Sci 1984;11:144-50. 